Correspondence

Per Halkjær Nielsen

phn@bio.aau.dk

Received 14 July 2007

Revised 27 November 2007

Accepted 2 December 2007

\section{Identity, abundance and ecophysiology of filamentous bacteria belonging to the Bacteroidetes present in activated sludge plants}

\author{
Caroline Kragelund, ${ }^{1}$ Caterina Levantesi, ${ }^{2}$ Arjan Borger, ${ }^{3}$ Karin Thelen, ${ }^{4}$ \\ Dick Eikelboom, ${ }^{5}$ Valter Tandoi, ${ }^{2}$ Yunhong Kong, ${ }^{1}$ Janneke Krooneman, ${ }^{6}$ \\ Poul Larsen, ${ }^{1}$ Trine Rolighed Thomsen ${ }^{1}$ and Per Halkjær Nielsen ${ }^{1}$ \\ ${ }^{1}$ Department of Biotechnology, Chemistry and Environmental Engineering, Aalborg University, \\ Sohngaardsholmsvej 57, DK-9000 Aalborg, Denmark \\ ${ }^{2}$ CNR, Water Research Institute, Via Reno 1, 00198 Rome, Italy \\ ${ }^{3}$ Grontmij, De Holle Bilt 22, 3732 HM De Bilt Postbus 203, 3730 AE De Bilt, The Netherlands \\ ${ }^{4}$ VERMICON AG, Emmy-Noether-Str. 2, 80992 Munich, Germany \\ ${ }^{5}$ ASIS vof, Deventerweg 38, 7203 AK Zutphen, The Netherlands \\ ${ }^{6}$ BIOCLEAR Environmental Biotechnology, Rozenburglaan 13, 9727 DL Groningen, The \\ Netherlands
}

\begin{abstract}
Filamentous members of the Bacteroidetes are commonly observed in activated sludge samples originating from both municipal and industrial wastewater treatment plants (WWTP), where they occasionally can cause bulking. Several oligonucleotide 16S rRNA-targeted probes were designed to target filaments with a needle-like appearance similar to Haliscomenobacter hydrossis. The design of these probes was based on an isolate and a sequence obtained from a micromanipulated filament. The abundance of filamentous Bacteroidetes was determined in 126 industrial samples applying already published and the newly developed probes. Small populations were found in $62 \%$ of the WWTP investigated. However, only relatively few WWTP (13\%) contained large populations of filamentous Bacteroidetes potentially responsible for bulking incidences. The identity of the most abundant filamentous Bacteroidetes with $\mathrm{H}$. hydrossis morphology could be detected by probes CFB719, SAP-309 and the newly designed probe HHY-654. A comprehensive study on the ecophysiology of probe-defined Bacteroidetes populations was conducted on Danish and Czech samples. The studies revealed that they were specialized bacteria involved in degradation of sugars, e.g. glucose and $N$-acetylglucosamine, and may participate in the conversion of lipopolysaccharides and peptidoglycan liberated by decaying cells. Many surface-associated exo-enzymes were excreted, e.g. chitinase, glucuronidase, esterase and phosphatase, supporting conversion of polysaccharides and possibly other released cell components. The role of filamentous bacteria with a $\mathrm{H}$. hydrossis-like morphology in the activated sludge ecosystem is discussed.
\end{abstract}

\section{INTRODUCTION}

Filamentous members of the phylum Bacteroidetes have been identified in different environments such as marine systems (Eilers et al., 2001), salt marshes (Lydell et al.,

Abbreviations: ELF, enzyme-labelled fluorescence; Fl, filament index; $\mathrm{FISH}$, fluorescence in situ hybridization; MAC, microsphere adhesion to cells; MAR, microautoradiography; WWTP, wastewater treatment plant(s).

The GenBank/EMBL/DDBJ accession numbers for the 16S rRNA gene sequences are DQ232755 for clone T5 (1466 bp) and DQ232756 for Iso10B (1422 bp).
2004) and activated sludge systems (Eikelboom, 2002; Jenkins et al., 2004; Kämpfer, 1995; Wagner et al., 1994). From activated sludge systems only Haliscomenobacter hydrossis within the Bacteroidetes has been isolated and characterized (Eikelboom, 1975; Kämpfer, 1995; van Veen et al., 1973; Williams \& Unz, 1985). This filamentous bacterium has been detected worldwide in activated sludge samples because of its easily recognizable morphological appearance: rigid straight filament, length between 10 and $200 \mu \mathrm{m}$, diameter between 0.3 and $0.5 \mu \mathrm{m}$ extending from the floc surface (thin needle-shape appearance) and Gramnegative staining (Eikelboom, 2006). Many surveys based 
on morphological characteristics identified $H$. hydrossis in bulking and foaming samples from the USA, several European countries, South Africa and Australia, all summarized by Jenkins et al. (2004). H. hydrossis was considered as rarely responsible for bulking and foaming, but was present in almost all wastewater treatment plants (WWTP) examined.

Identification of filamentous bacteria based on morphological identification can be ambiguous, so molecular methods such as fluorescence in situ hybridization (FISH) with oligonucleotide probes targeting different filamentous species are necessary for a reliable identification. Several gene probes have been designed to target members of Bacteroidetes (Manz et al., 1996; Schauer \& Hahn, 2005; Snaidr et al., 1999; Wagner et al., 1994). A species-specific probe (HHY) targeting $H$. hydrossis was designed based on the type strain DSM1100 (Wagner et al., 1994). Only one comprehensive FISH survey has been carried out using this probe (van der Waarde et al., 2002) and H. hydrossis was very frequently observed (present in $58 \%$ of the samples), but its abundance in these samples was not estimated. Furthermore, four additional filamentous organisms with a H. hydrossis-like morphology (but HHY-negative) were commonly observed (Eikelboom \& Geurkink, 2002), but the phylogenetic affiliation of these filaments was never resolved.

It is now apparent that many filamentous species are specialized feeders using a narrow range of substrate groups, e.g. the degradation of sugar and protein by Chloroflexi species (Kragelund et al., 2007). Other filamentous species can, on the other hand, take up a large range of different substrates, e.g. the filamentous Alphaproteobacteria (Kragelund et al., 2005, 2006). So it seems that many filamentous bacteria possess rather welldefined physiological and ecological traits, and if a better understanding of their ecophysiology is combined with knowledge on process conditions, better and more efficient control strategies may be developed.

Little is known about the physiology of filamentous Bacteroidetes in activated sludge. $H$. hydrossis isolates have been investigated in some detail and the studies report strictly aerobic bacteria capable of sugar degradation, especially glucose, and in some cases lactose and sucrose (Kämpfer, 1995; Krul, 1977; Mulder \& Deinema, 1992; van Veen et al., 1973, 1982). As far as we are aware, no study has been carried out directly in activated sludge samples so knowledge about in situ behaviour remains to be investigated. One biofilm study detected thin filamentous members of Bacteroidetes by applying gene probes targeting the genera Cytophaga and Flexibacter. Under aerobic conditions the filaments took up an amino acid mixture and $\mathrm{N}$-acetylglucosamine, but never acetate (Kindaichi et al., 2004).

In this study new $16 \mathrm{~S}$ rRNA-targeted probes were designed against additional $H$. hydrossis-like filaments and the identity and abundance of various filamentous Bacteroidetes in a number of industrial and municipal WWTP was investigated. Furthermore, the ecophysiology was investigated using a suite of in situ methods in combination with FISH.

\section{METHODS}

Activated sludge. In total, 126 samples from different industrial WWTP and five samples from municipal WWTP were used to monitor the presence and abundance of filamentous Bacteroidetes. Samples from WWTP treating industrial wastes were included: agro industry (6), brewery (2), chemical (27), dairy (10), fish (3), food (11), potato (12), pulp and paper (22), textile (5), tannery (4), other (13), domestic (4) and unknown (7). Samples were collected in Denmark, Italy, Poland, Germany and the Netherlands. Sixty-eight WWTP had nitrification and 58 of these also had denitrification.

Ecophysiological experiments were carried out with activated sludge from industrial and municipal WWTP from Denmark (Grenaa, Egaa, Ejby and AAE) and the Czech Republic (Svepravice and Main Prague). Plant descriptions are given in Table 1. All WWTP had nitrification and denitrification, and four also enhanced biological phosphorus removal. The temperature of the process tank varied and industrial WWTP were run at higher temperatures than most municipal WWTP. An anaerobic selector was present in one WWTP.

The activated sludge from the aeration tank was collected the day before the experiments were conducted and sent to Aalborg

Table 1. Major operational features of the wastewater treatment plants used in this study

\begin{tabular}{|c|c|c|c|c|c|c|}
\hline & Grenaa & AAE & Egaa & Ejby & Svepravice & Main Prague \\
\hline Nitrification & + & + & + & + & + & + \\
\hline Denitrification & + & + & + & + & + & + \\
\hline $\begin{array}{l}\text { Phosphorus removal (Biological/ } \\
\text { Chemical) }\end{array}$ & $\mathrm{B}$ & B & $\mathrm{B}$ & B & $\mathrm{Ch}$ & $\mathrm{Ch}$ \\
\hline Sludge age (days) & $35-40$ & $20-30$ & $20-25$ & $20-25$ & $?$ & $6-8$ \\
\hline Origin & Denmark & Denmark & Denmark & Denmark & Czech Republic & Czech Republic \\
\hline
\end{tabular}


(Denmark) by express mail. Undiluted sludge was used for exoenzyme and surface property experiments. In all other experiments the sludge was diluted to $1 \mathrm{~g}$ suspended solids $1^{-1}$ with nitrate and nitrite-free supernatant from the activated sludge.

Isolation, phylogenetic analysis and probe design. Isolate Iso10B was obtained in pure culture from a municipal WWTP by micromanipulation and morphologically identified as a $H$. hydrossislike filament. Isolate Iso10B was grown on IG and SCY media and could in addition grow on IGS (van Veen, 1973; van Veen et al., 1973). No further characterization of the isolate was done. Clone T5 originated from a micromanipulated filament with $H$. hydrossis-like morphology.

Amplification of 16S rRNA genes by PCR, purification of products and sequencing were performed as described by Levantesi et al. (2004). The sequences were edited using Sequencer DNA sequencing software (Gene Codes Inc.). Checks for chimeric sequences were conducted using the CHECK_CHIMERA program from the Ribosomal Database Project (http://rdp.cme.msu.edu) and the program BELLEROPHON (Hugenholtz \& Huber, 2003). 16S rRNA gene sequences of selected relatives within the phylum Bacteroidetes were compiled and aligned using the automatic nucleic acid aligner in the ARB software package (Ludwig et al., 2004), and alignments were refined manually. Aligned sequences were used for construction of trees by neighbour-joining, distance matrix, parsimony and maximumlikelihood approaches in the ARB software. Two different sequence conservation filters (the Bacteroidetes_chlorobi and the Bacteria filter of the ssu_jan04_corr_opt ARB database, available at http://www.arbhome.de) were applied and compared. Oligonucleotide probes were designed using the function provided in the ARB software. The specificity of these probes was further confirmed by using the Check Probe program in RDP (http://rdp.cme.msu.edu/probematch/ search.jsp). In order to evaluate the formamide concentration for optimum stringency, the designed probes were analysed on paraformaldehyde-fixed Iso10B culture applying hybridization buffer containing 0-60\% formamide (5\% increments) as well as the original activated sludge sample. Two new $16 \mathrm{~S}$ rRNA-targeted oligonucleotide probes were designed. HHY-654 (S-*-Hhy-654-a-A-18) was designed based on isolate Iso10B containing one mismatch to the HHY probe sequence. A degenerate base was introduced in that position so both Iso10B and the type strain for H. hydrossis (ATCC $27775^{\mathrm{T}}$ ) could be targeted. Probe HHY-T5 (S-*-Hhy-T5-654-a-A-18) was based on the sequence obtained by cell sorting/RT-PCR (reverse transcriptase PCR of a micromanipulated filament) (Levantesi et al., 2006). The optimal formamide concentration evaluated for both probes was determined to be $35 \%$ using activated sludge samples from where the isolate and RT-PCR product originated as well as on the pure culture. The closest relative of Iso10B and clone T5 was determined using
FASTA-Nucleotide Search available from http://www.ebi.ac.uk/fasta33/ nucleotide.html.

Identification and abundance. The filamentous bacteria present in industrial WWTP were morphologically identified using the Eikelboom classification system, and the filament index (FI) was noted as well (Eikelboom \& Geurking, 2000). FI determines the population size of the filamentous bacteria and ranges from 0 (no filaments) to 5 (very many). Furthermore, FISH was applied using $16 \mathrm{~S}$ rRNA-targeted nucleic acid probes (Loy et al., 2003) to fixed samples. FISH was conducted on fixed activated sludge samples and was performed according to Amann (1995). Oligonucleotide probes were labelled with 5(6)-carboxyfluorescein- $N$-hydroxysuccinimide ester (FLUOS) or with the sulfoindocyanine dyes (Cy3 and Cy5) (Biomers.net). A confocal laser scanning microscope, CLSM (LSM 510, Carl Zeiss), equipped with a UV laser (351 and $364 \mathrm{~nm}$ ), an Ar ion laser (458 and $488 \mathrm{~nm}$ ), and two HeNe lasers (543 and $633 \mathrm{~nm}$ ) was used to record fluorescent signals from these probes.

Identification and estimation of filament abundance within the phylum Bacteroidetes were performed by applying a selection of probes: some probes designed to target Bacteroidetes in different habitats [CFB286, CFB563 and CFB719 (Weller et al., 2000)], SAP-309 targeting the family Saprospiraceae (Schauer \& Hahn, 2005), probe HHY-654 targeting Iso10B and H. hydrossis (ATCC 27775, this study) and two species-specific probes targeting H. hydrossis [HHY (Wagner et al., 1994)] or the micromanipulated filament T5 (HHY-T5, this study). Hybridizations with probes targeting $H$. hydrossis-like species (probe HHY-654, HHY, HHY-T5) were carried out in combination with a corresponding hierarchical probe (e.g. probe CFB719 was the higher hierarchical level probe for HHY-T5 and SAP-309 was used for HHY and HHY-654; see Table 2). Specific probe details can be found in probeBase (Loy et al., 2003).

The combinations of FISH with MAR (microautoradiography), ELF (enzyme-labelled fluorescence) and MAC (microsphere adhesion to cells) (see below) were examined by CLSM prior to hybridization with gene probes except in the case of MAR-FISH, where hybridization were performed before applying the photographic emulsion. Positions of interest were recorded by an automatic stage controller and digital images of filaments were recorded. Fresh samples used for ELF and MAC were fixed in $4 \%$ paraformaldehyde for $1 \mathrm{~h}$ before the FISH procedure and the stage control enabled relocation of the microscopic field. Slight modification of MAC-FISH and ELF-FISH were necessary; for details see Kragelund et al. (2005).

Microautoradiography (MAR) and MAR-FISH. The MAR experiments were performed using ${ }^{3} \mathrm{H}$-labelled and ${ }^{14} \mathrm{C}$-labelled organic compounds and ${ }^{14} \mathrm{C}$-labelled bicarbonate. The procedure, which

Table 2. Overview of sequences targeted by the probes listed as percentages out of the total number of sequences published within different subgroups of Bacteroidetes phylum using RDPII (January 2008)

\begin{tabular}{|lccccccc|}
\hline & HHY-T5 & HHY & HHY-654 & SAP-309 & CFB719 & CFB563 \\
\hline Class Bacteroidetes & 0 & 0 & 0 & $<1 \%$ & $36 \%$ & $<1 \%$ & $35 \%$ \\
Class Flavobacteria & 0 & 0 & 0 & $<1 \%$ & $3 \%$ & $60 \%$ & $1 \%$ \\
Class Sphingobacteria & $<1 \%$ & $<1 \%$ & $<1 \%$ & $5 \%$ & $12 \%$ & $<1 \%$ & $3 \%$ \\
Family Saprospiraceae & $<1 \%$ & $2 \%$ & $3 \%$ & $53 \%$ & $29 \%$ & $<1 \%$ & 0 \\
Genus Haliscomenobacter & $<1 \%$ & $4 \%$ & $7 \%$ & $82 \%$ & $24 \%$ & 0 & 0 \\
H. hydrossis & 0 & $100 \%$ & $100 \%$ & $100 \%$ & 0 & 0 \\
Clone T5 & $100 \%$ & 0 & 0 & 0 & $100 \%$ & 0 \\
Iso10B & 0 & 0 & $100 \%$ & $100 \%$ & 0 & 0 \\
\hline
\end{tabular}

${ }^{\star}$ The type strain for H. hydrossis [DSM1100 (ATCC 27775)]. 
includes incubation, fixation and hybridization with gene probes, addition of a radiosensitive emulsion, exposure, processing, and microscopic evaluations, is described in detail in previous papers (Andreasen \& Nielsen, 1997; Lee et al., 1999; Nielsen et al., 2000). Various potential substrates were tested for uptake under aerobic conditions to determine whether gene-probe-defined representatives of Bacteroidetes were specialized or general consumers of organic substrates. For this, a selection of substrates were chosen representing short- and long-chain fatty acids, sugars, alcohols and amino acids. Also, potential use of other electron acceptors was tested by studying uptake of the same organic substrates with nitrate or nitrite present as electron acceptor or under strict anaerobic conditions (no oxygen, nitrate or nitrite present). A pre-incubation step of $2 \mathrm{~h}$ was included with unlabelled organic substrate $(2 \mathrm{mM})$ to ensure that only bacteria able to take up large quantities of the substrate under these conditions (for storage or growth) would be MAR-positive (Andreasen \& Nielsen, 2000). For analysis of potential uptake for all probe-defined Bacteroidetes, a minimum of 30 filaments of each probe-defined population was investigated in each incubation. In most experiments, MAR-positive and MAR-negative filaments were determined by comparing silver grain densities on top of filaments prior to the background level. Light microscopy was used to detect silver grains from MAR. Specific details of the procedure and the radiochemicals used in this study can be found elsewhere (Kragelund et al., 2007).

Enzyme-labelled fluorescence (ELF) and microsphere adhesion to cells (MAC). Presence of exo-enzyme activity was determined using ELF-97 (Molecular Probes). Investigations of cell surface hydrophobicity were performed using MAC (Molecular Probes). Details of exo-enzymes, microspheres and protocols are published elsewhere (Kragelund et al., 2005).

\section{RESULTS}

\section{Phylogenetic analysis}

The phylogenetic tree shown in Fig. 1 is based on publicly available 16S rRNA gene sequences consisting primarily of activated sludge clones and filamentous bacteria belonging to the phylum Bacteroidetes and it also includes the sequences of Iso10B and clone T5. The tree was inferred from neighbour-joining, maximum-parsimony and maximum-likelihood analysis, and two different conservation filters (the Bacteroidetes_chlorobi and the Bacteria filter of the ssu_jan04_corr_opt ARB database) did not alter the overall topology of the different treeing methods; the phylogenetic tree is depicted with the Bacteroidetes filter. Bootstrap values (maximum-parsimony with 1000 resamplings) were calculated using the Bacteroidetes_chlorobi filter. The phylogenetic position of isolate Iso10B and clone T5 was not completely resolved. The closest relative to Iso10B was identified as an uncultured member of the Saprospiraceae (AJ786323) (96\% sequence similarity) and this sequence always clustered together with Iso10B using the different treeing algorithms. The position of clone T5 switched depending on the algorithm but always grouped with the closest relative (DQ103646, 90\% sequence similarity,). Iso10B and clone T5 sequences affiliated within the genus Haliscomenobacter with a sequence similarity to the type strain $H$. hydrossis (ATCC 27775) of $95 \%$ and $86 \%$ for the isolate Iso10B and clone T5, respectively. These low similarities suggest potential novel species. The alignment used in phylogenetic analyses consisted of more than 1400 nucleotides except Candidatus Magnospira bakii (AF087057) and Saprospiraceae bacterium MS-Jaeger1-L (AJ786319), which were added to the trees using the 'add species to existing tree using parsimony' option of ARB.

Table 2 shows the coverage of the different probes applied to the members within the phylum Bacteroidetes, the family Saprospiraceae and the genus Haliscomenobacter given as percentages out of total number of sequences published (February 2007). The new probes HHY-654 and HHY-T5 both targeted sequences within the genus Haliscomenobacter, but no genus probe or family probe could detect all the new sequences at the same time. The probe that covered most of the family Saprospiraceae and the genus Haliscomenobacter sequences (SAP-309) only

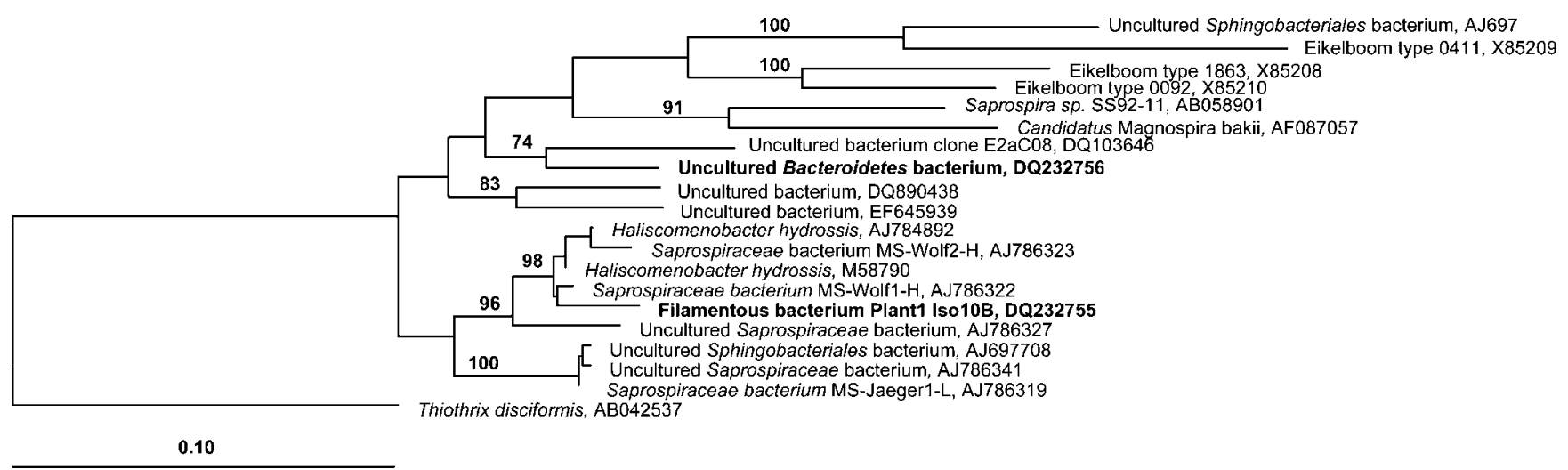

Fig. 1. 16S rRNA gene tree showing the phylogenetic affiliation of Iso10B and clone T5 within the phylum Bacteroidetes. The tree is based on maximum-likelihood analysis using the Bacteroidetes_chlorobi conservation filter; added bootstrap values were calculated using maximum parsimony. The scale bar corresponds to $10 \%$ sequence divergence. Thiothrix was chosen as outgroup. 
detected Iso10B and the type strain of $H$. hydrossis but not clone T5. Probe CFB719 targeted many sequences within the classes Bacteroidetes and Sphingobacteria, and also several sequences within the genus Haliscomenobacter, among others clone T5, but not Iso10B and H. hydrossis (ATCC 27775).

\section{Abundance}

A total of 126 WWTP were screened, and of these 104 had a total FI above 1.5 whereas 96 had a FI above 2.5, indicating potential bulking problems. In 75 of these plants, several filamentous species (co-dominating populations) were observed. By applying all the probes for Bacteroidetes shown in Table 2, H. hydrossis and $H$. hydrossis-like filaments were observed in 78 WWTP (62\%). In addition, other $H$. hydrossis-like filaments were observed based on morphological features in 24 additional WWTP, but they did not hybridize with any of the probes, so they may not belong to Bacteroidetes. No particular type of industrial waste favoured the presence of filamentous Bacteroidetes and they were found in plants with carbon removal and/or nitrification and/or denitrification. FISHdefined $H$. hydrossis and $H$. hydrossis-like filaments were often located inside the sludge flocs or protruding from these. They were rarely found outside except when the filament index exceeded 2.

Table 3 shows the data for the different FISH-defined $H$. hydrossis and H. hydrossis-like filaments. Probe HHY-T5 hybridized to filaments in 13 samples and these were abundant $(\mathrm{FI} \geqslant 2)$ in six cases. HHY-654 targeted filamentous populations in 53 WWTP and in 40 of these the filaments were also targeted by probe HHY. In two samples they constituted large populations $(\mathrm{FI} \geqslant 2)$. Most sequences within the family Saprospiraceae were theoretically covered by probe SAP-309 and probe-positive populations were detected in 57 WWTP; in three samples large populations were seen $(\mathrm{FI} \geqslant 2)$. Probe $\mathrm{CFB} 719$, covering primarily members of the class Bacteroidetes, but also some members of the Flavobacteria and Sphingobacteria, targeted filamentous populations in 25 WWTP and in seven samples the FI exceeded 2. In some cases, most epiphytic bacteria attached to morphotypes 0041/0675 filaments hybridized with this probe. Filamentous probe-defined populations belonging to the Flavobacteria targeted by CFB563 were found in 13 WWTP and in two cases FI was above 2.

The more specific probes applied, HHY-654, HHY and HHY-T5, mainly targeted filaments fitting the descriptions of Eikelboom (2002) and Jenkins et al. (2004). However, in some cases their morphology differed from that considered typical for this filament; e.g. diameter up to $1.0 \mu \mathrm{m}$ and the shape of filaments sometimes appeared more curled compared to the more typical needle-like appearance. The broad gene probes CFB563 and CFB719 in some cases targeted both single cells and epiphytic growth on certain filamentous species as well as some $H$. hydrossis-like filaments. The morphologies of these $H$. hydrossis-like filaments were often somewhat more curled compared to the normal needle-shape appearance of $H$. hydrossis.

\section{Ecophysiology}

Substrate assimilation profile. Uptake of various substrates under aerobic conditions by probe-defined filamentous Bacteroidetes is shown in Table 4. No activity was ever observed when samples were incubated under anaerobic or anoxic (with either nitrate or nitrite as electron acceptors) conditions. All substrates tested were taken up by some floc-forming bacteria or single cells during all incubation conditions, hence serving as positive controls.

Only very few tested substrates were taken up in situ by these relatively abundant filamentous Bacteroidetes in the WWTP examined. Some short-chain fatty acids and sugars were taken up by the probe-defined species (Table 4). In general, all filamentous Bacteroidetes could take up glucose and propionate but never acetate. Filaments hybridizing with the specific probe (HHY) showed a very consistent uptake pattern in all samples investigated, whereas the filaments hybridizing with the broader CFB719 probe showed minor variations. In three WWTP (AAE, Egaa and

Table 3. Overview of FISH survey conducted on 126 mainly industrial WWTP

The numbers of treatment plants containing filaments hybridizing with the probes are shown.

\begin{tabular}{|llcrc|}
\hline FISH probe & Target $\boldsymbol{H}$. hydrossis sequences & $\begin{array}{c}\text { No. of WWTP in which } \\
\text { present }\end{array}$ & FI $>\mathbf{1 . 5}$ & FI $<\mathbf{2 . 5}$ \\
\hline HHY-T5 & Clone T5 & 13 & 6 & 4 \\
HHY & H. hydrossis & 40 & 7 & 2 \\
HHY-654 & H. hydrossis and Iso10B & 53 & 13 & 2 \\
SAP-309 & H. hydrossis and Iso10B & 53 & 3 & 3 \\
CFB719 & Clone T5 & 25 & 7 & 4 \\
CFB286 & - & 0 & 0 & 0 \\
CFB563 & - & 13 & 2 & 1 \\
\hline
\end{tabular}

*The type strain for H. hydrossis [DSM1100 (ATCC 27775)]. 
Table 4. Uptake of substrates by the different probe-defined filamentous Bacteroidetes under aerobic conditions as investigated by MAR

ND, Not determined; -, no silver grains (no substrate uptake); $(+)$, some filaments slightly positive, some silver grains; + , clear silver grain formation.

\begin{tabular}{|c|c|c|c|c|c|c|c|c|}
\hline & \multicolumn{4}{|c|}{ HHY } & \multicolumn{4}{|c|}{ CFB 719 (HHY negative) } \\
\hline & Svepravice & Main Prague & Ejby & Egaa & Grenaa & AAE & Ejby & Egaa \\
\hline Acetate & - & - & - & - & - & - & - & - \\
\hline Propionate & + & + & + & + & - & + & + & + \\
\hline Pyruvate & $\mathrm{ND}$ & $\mathrm{ND}$ & $\mathrm{ND}$ & $\mathrm{ND}$ & - & - & $\mathrm{ND}$ & $\mathrm{ND}$ \\
\hline Mannose & ND & ND & - & - & - & - & - & - \\
\hline Galactose & ND & ND & - & - & - & - & - & - \\
\hline$N$-Acetylglucosamine & $\mathrm{ND}$ & $\mathrm{ND}$ & + & + & $\mathrm{ND}$ & + & $(+)$ & - \\
\hline Leucine & - & - & - & - & - & - & - & - \\
\hline Glycine & ND & $\mathrm{ND}$ & - & - & - & - & - & - \\
\hline
\end{tabular}

Ejby), $N$-acetylglucosamine was tested and uptake was evident in all plants.

Surface properties and exo-enzymic activity. The distribution of hydrophobic and hydrophilic cell surfaces was investigated in three different sludges by MAC (see Table 5). Parts of the flocs were covered in microspheres and other parts had no microspheres, thus acting as controls. All filamentous bacteria with a $H$. hydrossis-like morphology protruding from sludge flocs appeared hydrophilic (no hydrophobic spheres attached) whereas other filamentous bacteria present, e.g. Candidatus Microthrix parvicella, were hydrophobic, as were certain parts of the sludge flocs.

Presence of exo-enzyme activity in the sludge flocs and on the filament surfaces was determined by the ELF assay in five plants (Table 5). Sludge flocs from all plants exhibited exo-enzyme activity for all enzymes tested, although some

Table 5. Surface properties and exo-enzymic activity of probe-defined filamentous Bacteroidetes determined by MAC and ELF, respectively

ND, Not determined; Chit, chitinase; Est, esterase; Glu, glucuronidase; $\mathrm{PO}_{4}$, phosphatase.

\begin{tabular}{|llll|}
\hline WWTP & $\begin{array}{c}\text { Gene-probe-defined } \\
\text { filament }\end{array}$ & $\begin{array}{c}\text { Surface } \\
\text { properties }\end{array}$ & Exo-enzymes \\
\hline Svepravice & HHY & ND & Glu, Est, PO $_{4}$ \\
Main Prague & HHY & ND & Glu, Est, Chit \\
Egaa & HHY + CFB719 & Hydrophilic & Glu, PO \\
Ejby & HHY + CFB719 & Hydrophilic & Glu, Chit \\
AAE & CFB719 & Hydrophilic & Glu, Chit \\
\hline
\end{tabular}

activity was low (e.g. lipase) and others very high (e.g. esterase). Probe-defined $H$. hydrossis and $H$. hydrossis-like filaments excreted glucuronidase. Esterase activity was observed in two WWTP. Chitinase activity was detected in AAE, Ejby and Main Prague and also some phosphatase activity was observed (Svepravice and Egaa).

\section{DISCUSSION}

\section{Identity and abundance}

The FISH survey performed on 126 WWTP showed the presence of probe-defined filamentous Bacteroidetes in $62 \%$ of the activated sludge samples originating from different industrial and municipal WWTP. These filamentous bacteria were found in many different types of activated sludge and most often they were present in relatively low amounts $(\mathrm{FI}<1.5)$. In $13 \%$ of the samples, the FI was above 2.5, indicating their potential involvement in bulking in these WWTPs. These results confirmed a previous FISH survey on a large number of industrial WWTP (van der Waarde et al., 2002).

In this study, two new probes targeting filamentous bacteria within the genus Haliscomenobacter were designed and applied. One probe (HHY-654) is broader than the specific probe HHY published by Wagner et al. (1994), and the other more specifically targets a sequence obtained by cell sorting/RT-PCR from a micromanipulated filament (HHY-T5). The two probes proved to be very useful when investigating the $H$. hydrossis-like species in activated sludge plants. Using the HHY probe, filamentous $H$. hydrossis was detected in $32 \%$ of the samples. However, when the new probe was also applied, filamentous $H$. hydrossis-like bacteria within the genus Haliscomenobacter 
were detected in $52 \%$ of the samples. This shows that use of only probe HHY underestimates the abundance of $H$. hydrossis-like bacteria, and that particularly the abundant species related to the probe HHY-T5 sequence would not be detected. This stresses that it may be difficult to isolate the dominant filamentous Bacteroidetes by standard methods, so use of culture-independent methods is necessary for identification of these bacteria. Probe CFB719 gave a positive signal in 25 WWTP, where 13 $(52 \%)$ of these were actually identical to HHY-T5-defined populations due to probe overlap (for details, see Table 2). This suggests that new species are likely to exist in the remaining 12 plants ( $48 \%$ ), where no existing probe could target the filaments. The thin $H$. hydrossis-like filaments detected by CFB563 (targeting primarily Flavobacteria) are also most likely undescribed species and more specific gene probes are necessary for their individual detection. At present, CFB719 and SAP-309 can be used in combination for detection of all (or most) H. hydrossis and H. hydrossislike bacteria.

\section{Ecophysiology}

The filamentous probe-defined $H$. hydrossis and $H$. hydrossis-like filaments were only observed to take up very few substrates and only under aerobic conditions. The same substrate uptake pattern was observed regardless of the probe-defined populations (HHY, HHY-T5 and CFB719) as they all took up some sugars and propionate and thus appear to be relatively specialized in aerobic sugar degradation. Together with the other properties (see below), this shows that they are most likely so similar in their physiology that they can be regarded as one group and can all be detected by applying the relatively broad gene probes (CFB719 and SAP-309).

Uptake of $N$-acetylglucosamine units is not commonly observed among bacteria present in WWTP (P. H. Nielsen \& C. Kragelund, unpublished results). N-Acetylglucosamine units are found in lipopolysaccharides and in peptidoglycan components liberated from decaying cells (Barker \& Stuckey, 1999). As continuous degradation of cells occurs in WWTP, $N$-acetylglucosamine units may support the growth of these filamentous Bacteroidetes species and explain their presence in many WWTP. Uptake of $N$-acetylglucosamine and amino acid mixture by thin filamentous Bacteroidetes has also been observed in an autotrophic biofilm originating from a municipal WWTP and grown in a lab reactor (Kindaichi et al., 2004). Filaments targeted by probe CF319a $+\mathrm{b}$ were responsible for the conversion of $64 \%$ of the $N$-acetylglucosamine even though the bacterial abundance constituted just $2 \%$ of the community (Kindaichi et al., 2004). Our study also showed that several exo-enzymes, such as glucuronidase, esterase and chitinase, were excreted by the $H$. hydrossis-like filaments, which could aid in the breakdown of the polysaccharides. Exo-enzymic breakdown of peptidoglycan or lipopolysaccharides into $\mathrm{N}$-acetylglucosamine units would assist in continuous substrate supply for the bacteria and provide a highly specialized niche in WWPT. This specialization on sugars and polysaccharides has been confirmed by pure culture studies on $H$. hydrossis (Kämpfer, 1995; Krul, 1977; Mulder \& Deinema, 1992; van Veen et al., 1973, 1982). In one study, only growth on a few sugars and hydrolysis of $N$-acetyl- $\beta$-glucosaminide and $\mathrm{N}$-acetylglucosamine were observed out of 240 different organic substrates tested (Kämpfer, 1995). Also, other reports exist for members of Cytophagales being chitinolytic in other environments, especially in marine systems, shown by pure culture work or by MAR (Baty et al., 2000, 2001; Kämpfer, 1995; Ouverney \& Fuhrman, 1999; Reichenbach, 1999).

Thin filamentous Bacteroidetes appear to be present in most WWTP, both municipal and industrial, but are rarely involved in bulking or foaming incidences, so although they contribute to the overall filament index of the sample, preventive actions to exclude these filaments from WWTPs seem not to be of high importance. However, in rare cases where they cause problems control is needed. This study has given important information about the physiology of these bacteria, but has also shown that there is no obvious control measure. Based upon their specialization on sugar degradation and conversion of dead microbial cells, it would be impossible to remove the substrates sustaining their growth in order to limit their abundance in WWTP. Metabolic selection, where changes between aerobic conditions and conditions under which the bacteria are unable to grow (anoxic and strict anaerobic conditions) has been suggested as a potential control measure against many filamentous bacteria (Wanner, 1994). However, metabolic selection does not appear to be sufficient to completely suppress the presence of these thin filamentous Bacteroidetes. In many of the WWTP investigated, different process configurations (nitrification/denitrification and enhanced biological phosphorus removal) were in fact included and still populations of $H$. hydrossis and $H$. hydrossis-like filaments were detected. This may be due to a high resistance to starvation as proposed by Chiesa \& Irvine (1985), and the specialized niche with the ability to take up $N$-acetylglucosamine and similar compounds that they share with only a few other bacteria such as Chloroflexi (Kindaichi et al., 2004; Kragelund et al., 2007).

\section{ACKNOWLEDGEMENTS}

This study was funded by the EU programme 'Dynamics and composition of filamentous micro-organism communities in industrial water systems' (DYNAFILM). Jane Ildal and Marianne Stevenson are both acknowledged for their assistance.

\section{REFERENCES}

Amann, R. I. (1995). In situ identification of micro-organisms by whole cell hybridization with rRNA-targeted nucleic acid probes. In Molecular Microbial Ecological Manual, pp. 1-15. Edited by A. D. L. 
Akkermans, J. D. van Elsas \& F. J. de Bruijn. London: Kluwer Academic Publications.

Andreasen, K. \& Nielsen, P. H. (1997). Application of microautoradiography to the study of substrate uptake by filamentous microorganisms in activated sludge. Appl Environ Microbiol 63, 3662-3668.

Andreasen, K. \& Nielsen, P. H. (2000). Growth of Microthrix parvicella in nutrient removal activated sludge plants: studies of in situ physiology. Water Res 34, 1559-1569.

Barker, D. J. \& Stuckey, D. C. (1999). A review of soluble microbial products (SMP) in wastewater treatment systems. Water Res 33, 3063-3082.

Baty, A. M., Eastburn, C. C., Diwu, Z., Techkarnjanaruk, S., Goodman, A. E. \& Geesey, G. G. (2000). Differentiation of chitinase-active and non-chitinase-active subpopulations of a marine bacterium during chitin degradation. Appl Environ Microbiol 66, 3566-3573.

Baty, A. M., Diwu, Z., Dunham, G., Eastburn, C. C., Geesey, G. G., Goodman, A. E., Suci, P. A. \& Techkarnjanaruk, S. (2001). Characterization of extracellular chitinolytic activity in biofilms. Methods Enzymol 336, 279-301.

Chiesa, S. C. \& Irvine, R. L. (1985). Growth and control of filamentous microbes in activated sludge - an integrated hypothesis. Water Res 19, 471-479.

Eikelboom, D. H. (1975). Filamentous organisms observed in activated sludge. Water Res $\mathbf{9}, 365-388$.

Eikelboom, D. H. (2002). Process Control of Activated Sludge Plants by Microscopic Investigation. London, UK: IWA Publishing.

Eikelboom, D. H. (2006). Identification and Control of Filamentous Microorganisms in Industrial Wastewater Treatment Plants. London, UK: IWA Publishing.

Eikelboom, D. \& Geurkink, B. (2000). Catalogue of Filamentous Microorganisms Occurring in Industrial Activated Sludge Plants. TNOMEP. Report R 2001.

Eikelboom, D. H. \& Geurkink, B. (2002). Filamentous microorganisms observed in industrial activated sludge plants. Water Sci Technol 46, 535-542.

Eilers, H., Pernthaler, J., Peplies, J., Glöckner, F. O., Gerdts, G. \& Amann, R. (2001). Isolation of novel pelagic bacteria from the German Bight and their seasonal contributions to surface picoplankton. Appl Environ Microbiol 67, 5134-5142.

Hugenholtz, P. \& Huber, T. (2003). Chimeric $16 \mathrm{~S}$ rDNA sequences of diverse origin are accumulating in the public databases. Int J Syst Evol Microbiol 53, 289-293.

Jenkins, D., Richard, M. G. \& Daigger, G. T. (2004). Manual on the Causes and Control of Activated Sludge Bulking, Foaming, and Other Solids Separation Problems. London: Lewis Publishers.

Kämpfer, P. (1995). Physiological and chemotaxonomic characterization of filamentous bacteria belonging to the genus Haliscomenobacter. Syst Appl Microbiol 18, 363-367.

Kindaichi, T., Ito, T. \& Okabe, S. (2004). Ecophysiological interaction between nitrifying bacteria and heterotrophic bacteria in autotrophic nitrifying biofilms as determined by microautoradiography-fluorescence in situ hybridization. Appl Environ Microbiol 70, 1641-1650.

Kragelund, C., Nielsen, J. L., Thomsen, T. R. \& Nielsen, P. H. (2005). Ecophysiology of the filamentous Alphaproteobacterium Meganema perideroedes in activated sludge. FEMS Microbiol Ecol 54, 111-122.

Kragelund, C., Kong, Y., van der Waarde, J., Thelen, K., Eikelboom, D., Tandoi, V., Thomsen, T. R. \& Nielsen, P. H. (2006). Ecophysiology of different filamentous Alphaproteobacteria species from industrial waste water treatment plants. Microbiology 152, 3003-3012.
Kragelund, C., Levantesi, C., Borger, A., Thelen, K., Eikelboom, D., Tandoi, V., Kong, Y., van der Waarde, J., Krooneman, J. \& other authors (2007). Identity, abundance and ecophysiology of different filamentous Chloroflexi species from activated sludge treatment plants. FEMS Microbiol Ecol 59, 671-682.

Krul, J. M. (1977). Experiments with Haliscomenobacter hydrossis in continuous culture without and with Zoogloea ramigera. Water Res 11, 197-204.

Lee, N., Nielsen, P. H., Andreasen, K. H., Juretschko, S., Nielsen, J. L., Schleifer, K. H. \& Wagner, M. (1999). Combination of fluorescent in situ hybridization and microautoradiography - a new tool for structure-function analyses in microbial ecology. Appl Environ Microbiol 65, 1289-1297.

Levantesi, C., Beimfohr, C., Geurkink, B., Rossetti, S., Thelen, K., Krooneman, J., Snaidr, J., van der Waarde, J. \& Tandoi, V. (2004). Filamentous Alphaproteobacteria associated with bulking in industrial wastewater treatment plants. Syst Appl Microbiol 27, 716-727.

Levantesi, C., Rossetti, S., Beimfohr, C., Thelen, K., Krooneman, J., van der Waarde, J. \& Tandoi, V. (2006). Description of filamentous bacteria present in industrial activated sludge WWTPs by conventional and molecular methods. Water Sci Technol 54, 129-137.

Loy, A., Horn, M. \& Wagner, M. (2003). probeBase: an online resource for rRNA-targeted oligonucleotide probes. Nucleic Acids Res 31, 514-516.

Ludwig, W., Strunk, O., Westram, R., Richter, L., Meier, H., Yadhukumar, Buchner, A., Lai, T., Steppi, S. \& other authors (2004). ARB: a software environment for sequence data. Nucleic Acids Res 32, 1363-1371.

Lydell, C., Dowell, L., Sikaroodi, M., Gillevet, P. \& Emerson, D. (2004). A population survey of members of the phylum Bacteroidetes isolated from salt marsh sediments along the East Coast of the United States. Microb Ecol 48, 263-273.

Manz, W., Amann, R., Ludwig, W., Vancanneyt, M. \& Schleifer, K. H. (1996). Application of a suite of $16 \mathrm{~S}$ rRNA-specific oligonucleotide probes designed to investigate bacteria of the phylum CytophagaFlavobacter-Bacteroides in the natural environment. Microbiology 142, 1097-1106.

Mulder, E. G. \& Deinema, M. H. (1992). The sheathed bacteria. In The Prokaryotes: a Handbook on the Biology of Bacteria: Ecophysiology, Isolation, Identification, Application, 2nd edn, pp. 2612-2624. Edited by A. Balows, H. G. Trüper, M. Dworkin, W. Harder \& K. H. Schleifer. New York: Springer-Verlag.

Nielsen, P. H., de Muro, M. A. \& Nielsen, J. L. (2000). Studies on the in situ physiology of Thiothrix spp. present in activated sludge. Environ Microbiol 2, 389-398.

Ouverney, C. C. \& Fuhrman, J. A. (1999). Combined microautoradiography-16S rRNA probe technique for determination of radioisotope uptake by specific microbial cell types in situ. Appl Environ Microbiol 65, 1746-1752.

Reichenbach, H. (1999). The Order Cytophagales. In The Prokaryotes: an Evolving Electronic Resource for the Microbiological Community, 3rd edn. Edited by M. Dworkin. New York: Springer-Verlag.

Schauer, M. \& Hahn, M. W. (2005). Diversity and phylogenetic affiliations of morphologically conspicuous large filamentous bacteria occurring in the pelagic zones of a broad spectrum of freshwater habitats. Appl Environ Microbiol 71, 1931-1940.

Snaidr, J., Fuchs, B., Wallner, G., Wagner, M., Schleifer, K. H. \& Amann, R. (1999). Phylogeny and in situ identification of a morphologically conspicuous bacterium, Candidatus Magnospira bakii, present at very low frequency in activated sludge. Environ Microbiol 1, 125-135.

van der Waarde, J., Krooneman, J., Geurkink, B., van der Werf, A., Eikelboom, D., Beimfohr, C., Snaidr, J., Levantesi, C. \& Tandoi, V. 
(2002). Molecular monitoring of bulking sludge in industrial wastewater treatment plants. Water Sci Technol 46, 551-558.

van Veen, W. L. (1973). Bacteriology of activated-sludge, in particular filamentous bacteria. Antonie Van Leeuwenhoek 39, 189-205.

van Veen, W. L., van der Kooij, D., Geuze, E. C. \& van der Vlies, A. W. (1973). Investigations on sheathed bacterium Haliscomenobacter hydrossis gen. nov., sp. nov., isolated from activated sludge. Antonie Van Leeuwenhoek 39, 207-216.

van Veen, W. L., Krul, J. M. \& Bulder, C. J. E. A. (1982). Some growthparameters of Haliscomenobacter hydrossis (Syn. Streptothrix hyalina) a bacterium occurring in bulking activated sludge. Water Res 16, 531-534.

Wagner, M., Amann, R., Kämpfer, P., Assmus, B., Hartmann, A., Hutzler, P., Springer, N. \& Schleifer, K. H. (1994). Identification and in situ detection of Gram-negative filamentous bacteria in activated sludge. Syst Appl Microbiol 17, 405-417.

Wanner, J. (1994). Activated Sludge Bulking and Foaming Control. Basel: Technomic Publishing Company.

Weller, R., Glöckner, F. O. \& Amann, R. (2000). 16S rRNA-targeted oligonucleotide probes for the in situ detection of members of the phylum Cytophaga-Flavobacterium-Bacteroides. Syst Appl Microbiol 23, 107-114.

Williams, T. M. \& Unz, R. F. (1985). Isolation and characterization of filamentous bacteria present in bulking activated-sludge. Appl Microbiol Biotechnol 22, 273-282.

Edited by: H. Daims 